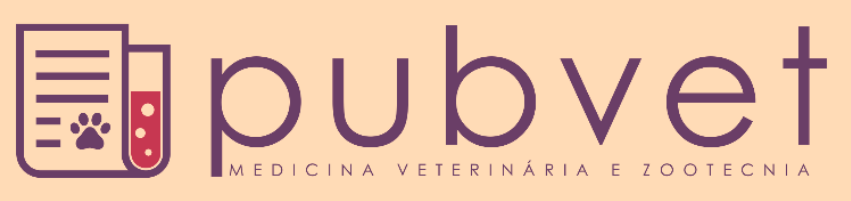

https://doi.org/10.31533/pubvet.v16n01a1005.1-6

\title{
Esporotricose felina: Relatos de caso
}

\author{
Ticiana Machado Guimarães ${ }^{1 *}$, André Barreto Guimarães ${ }^{2}$ \\ ${ }^{I}$ Médica Veterinária Autônoma, especialista em clínica médica de felinos domésticos, Salvador, BA - Brasil. \\ ${ }^{2}$ Médico Veterinário Autônomo, especialista em neurologia veterinária e animais silvestres, Salvador, BA - Brasil. \\ *Autor para correspondência, E-mail: ticimev@yahoo.com.br
}

\begin{abstract}
Resumo. A esporotricose felina é uma micose subcutânea de evolução subaguda e crônica, cujo agente etiológico é um fungo dimórfico e geofílico do complexo Sporothrix (Sporothrix schenckii). A transmissão zoonótica vem recebendo destaque, tendo os felinos domésticos um papel epidemiológico importante na disseminação da enfermidade. Apesar de ser uma zoonose, existem poucos relatos de casos de esporotricose no nordeste do Brasil. Este artigo tem como objetivo descrever e relatar casos de esporotricose felina em dois gatos atendidos no consultório veterinário Mascot Pet, alertando os médicos veterinários para este possível diagnóstico. Ambos apresentavam lesões ulcerativas na pele, tendo um deles crostas e pequenas pápulas hiperêmicas. Foram realizadas citologias por imprint de lâminas no consultório e realizada a técnica de microscopia com coloração de Romanowsky pelo laboratório veterinário Vetinlab, na Bahia, por meio da qual observou-se estruturas leveduriformes compatíveis com o agente Sporothrix schenckii. Um dos animais foi tratado com Itraconazol $50 \mathrm{mg} / \mathrm{animal}$ a cada 24 horas, por um período de quatro meses com sucesso. Entretanto, foi necessária a eutanásia em um dos felinos, realizada pelo centro de controle de zoonoses de Salvador, Bahia.
\end{abstract}

Palavras-chave: Esporotricose, felino, micose, Sporothrix schenkii, zoonose

\section{Feline sporotrichosis: Case reports}

\begin{abstract}
Feline sporotrichosis is a subcutaneous mycosis of subacute and chronic evolution, whose etiologic agent is a dimorphic and geophilic fungus of the Sporothrix complex (Sporothrix schenckii). Zoonotic transmission has been highlighted, with domestic felines playing an important epidemiological role in the spread of the disease. Despite being a zoonosis, there are few case reports of sporotrichosis in northeastern Brazil. This article aims to describe and report cases of feline sporotrichosis in two cats seen at the Mascot Pet veterinary office, alerting veterinarians to this possible diagnosis. Both had ulcerative skin lesions, one of them having crusts and small hyperemic papules. Imprint cytology of slides was performed in the office and the microscopy technique with Romanowsky staining was performed by the veterinary laboratory Vetinlab, in Bahia, through which yeast-like structures compatible with the agent Sporothrix schenckii were observed. One of the animals was successfully treated with Itraconazole $50 \mathrm{mg} / \mathrm{animal}$ every 24 hours for a period of four months. However, euthanasia was necessary in one of the cats, performed by the zoonoses control center in Salvador, Bahia.
\end{abstract}

Keywords: Feline, mycosis, sporotrichosis, Sporothrix schenkii, zoonosis

\section{Introdução}

A esporotricose é uma micose subcutânea causada pelo fungo Sporothrix schenckii, que acomete homens e animais, sendo uma importante zoonose (Almeida et al., 2018; Gonçalves et al., 2019; Rosa et al., 2017). Esta doença pode ter evolução subaguda ou crônica e seu agente etiológico é um fungo 
dimórfico e geofílico (Almeida et al., 2018). O S. schenckii causa uma enfermidade subcutânea piogranulomatosa, com ampla distribuição mundial, se apresenta na forma micelial, entre $25^{\circ} \mathrm{C}$ e $30^{\circ}$ C. É considerado sapróbio de cascas de árvores e de solos ricos em matéria orgânica e vegetação, crescendo principalmente em locais quentes e úmidos (Araujo et al., 2020; Araujo \& Leal, 2016; Barros et al., 2012). O Sporothrix vive na forma filamentosa e, após haver a inoculação no hospedeiro ou em cultivos com temperaturas de $37^{\circ} \mathrm{C}$ ocorre a transição para sua fase leveduriforme (Cavalcanti et al., 2018; Pires, 2017).

Segundo Barros et al. (2010) foi descrita, primeiramente em 1898, nos EUA, por Benjamin Schenck. A enfermidade prevalece nos EUA; porém, com maior importância epidemiológica no México e no Brasil (Larsson, 2011). A esporotricose está presente em diversos países do mundo. Na China encontrase, predominantemente, S. globosa; na África do Sul é mais comum a $S$. schenkii e no Brasil a $S$. brasiliensis. A doença ocorre com menor frequência no Japão, Austrália, Índia e Europa, embora seja considerado um fungo cosmopolita (Cavalcanti et al., 2018; Pires, 2017). No Brasil é considerada uma doença endêmica no Rio de Janeiro, onde possui cerca de oito mil casos entre humanos e animais e na região sul do estado do Rio Grande do Sul, onde existem cerca de mil casos confirmados pelo laboratório de Micologia da Universidade Federal de Pelotas (Cavalcanti et al., 2018; Pires, 2017). Recentemente, o aumento do número de casos no estado de São Paulo motivou a publicação da Portaria n*064/2016, na cidade de Guarulhos que determina a notificação compulsória dos casos humanos suspeitos e confirmados (Secretaria Municipal de Guarulhos, 2016).

Apesar de ser uma zoonose, existem poucos relatos de casos de esporotricose no nordeste do Brasil (Araujo \& Leal, 2016; Nunes et al., 2013). Este artigo tem como objetivo descrever e relatar casos de esporotricose felina em dois gatos atendidos no consultório veterinário Mascot Pet, localizado no bairro de Stella Maris, situado no litoral norte da cidade de Salvador, Bahia, mostrando a diferença entre um caso mais complexo, com lesões de pele generalizadas e comprometimento sistêmico do animal e um caso com uma única lesão localizada, sem comprometimento no estado geral do animal. Além disso, visa confirmar a crescente ocorrência da doença no Nordeste do país, mais especificamente, na região metropolitana de Salvador, Bahia.

\section{Relato de caso}

Em novembro de 2017, o Centro de Controle de Zoonoses (CCZ) alertou o Centro de Informações Estratégicas em Vigilância em Saúde (CIEVS) de Salvador sobre um crescimento do número de felinos acometidos com esporotricose na região metropolitana de Salvador e, a partir de março de 2018, esta doença passou a ser de notificação compulsória nesta cidade, através da portaria nº 191/2018 (Secretaria Municipal de Saúde de Salvador, 2019).

Casos de esporotricose começaram a surgir nas clínicas veterinárias da cidade citada. Em 2018 o consultório veterinário Mascot Pet atendeu três casos confirmados com exames laboratoriais e um caso suspeito por vínculo clínico-epidemiológico. No ano de 2019, a Mascot Pet atendeu mais quatro casos confirmados laboratorialmente, em 2020 mais dois casos e em 2021 mais dois casos, todos confirmados com exames.

Os animais que fizeram parte deste relato de caso chegaram a este consultório para atendimento, ambos com lesões cutâneas ulceradas. O primeiro felino macho, não castrado, idade aproximada de dois anos, sem raça definida, foi atendido em 9 de setembro de 2020, em meio à pandemia de COVID19. Os proprietários estavam passando os dias na casa de praia da família, situada no condomínio Interlagos, na cidade de Camaçari, Bahia e adotaram o animal na rua, com múltiplas lesões na pele, ulceradas (Figura 1), apatia e hiporexia e o apelidaram de Capitão. Na avaliação dermatológica foram observadas lesões cutâneas ulceradas, crostas, pápulas e feridas em todo o corpo do animal, além de mucosas hipocoradas, estado corporal debilitado, sinais de desnutrição com ossatura aparente á palpação. $\mathrm{O}$ segundo animal era um felino macho, semi-domiciliar, castrado, sem raça definida, quatro anos de idade, com livre acesso à rua. Este segundo animal, que atende pelo nome de Max, foi examinado em 6 de março de 2021. Apresentava apenas uma lesão localizada, ulcerada, arredondada, em região sacral lateral (Figura 2). O animal Max não apresentava nenhuma alteração em seu estado geral, além da lesão localizada. Foi realizada, em ambos os pacientes, o imprint de lâminas nas lesões para exame citológico. O material coletado foi posto em lâminas de vidro e coradas pelo método de Romanowsky (igura 3), 
realizada pelo laboratório Vetinlab. As lâminas coradas foram analisadas em microscopia eletrônica e foi observada a presença de estruturas leveduriformes compatíveis com fungos do complexo Sporothrix spp (Figura 4).

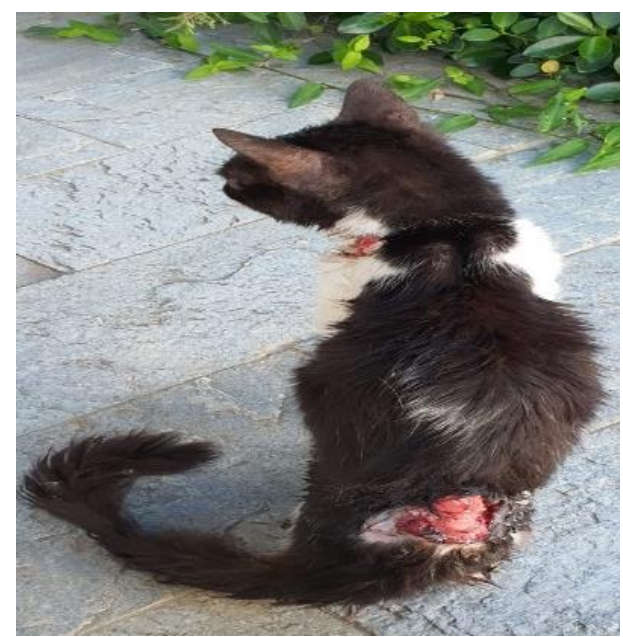

Figura 1. Animal com múltiplas lesões de pele ulceradas.

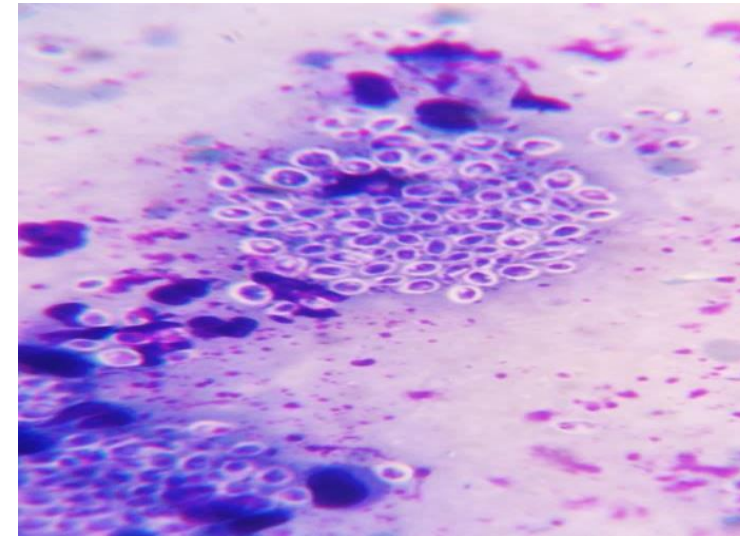

Figura 3. Lâmina corada pelo método Romanowsky.

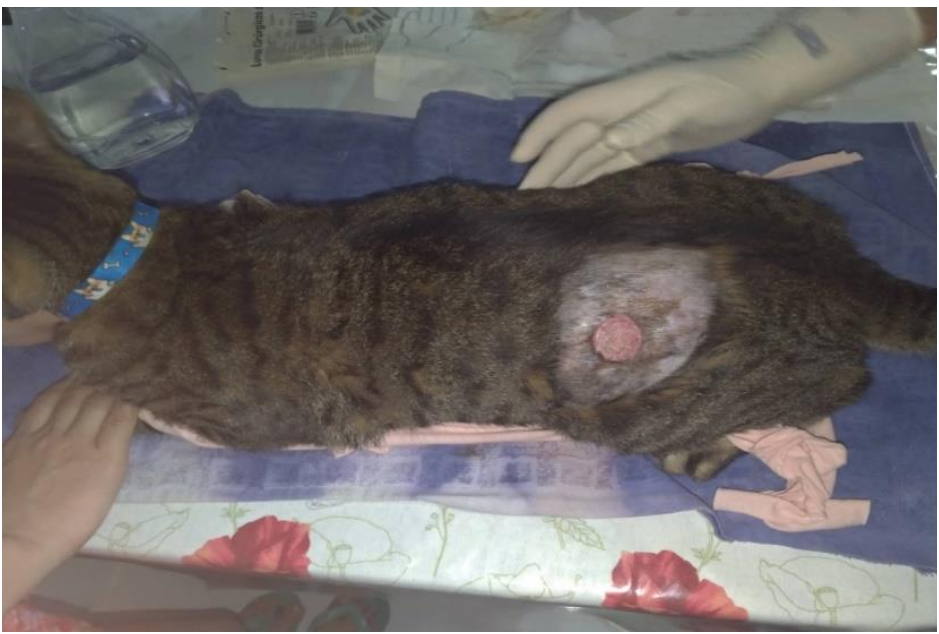

Figura 2. Animal com única lesão ulcerada.

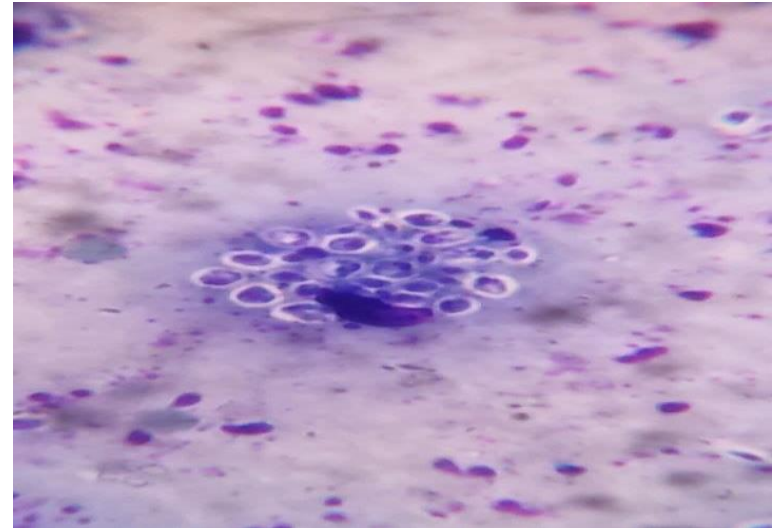

Figura 4. Lâmina com presença de estrutura leveduriforme compatível com Sporothrix spp.

O primeiro animal, Capitão, como tratava-se de animal de rua, apresentava lesões significativas generalizadas, com aspecto bastante repulsivo (Figuras 5 e 6). Foi notificado ao Centro de Controle de Zoonoses de Salvador, pois os proprietários queriam levar o animal para a casa onde tinham residência na cidade, apesar do animal ter sido encontrado na cidade de Camaçari, na região metropolitana de Salvador. Porém, após o diagnóstico de Esporotricose e devido aos proprietários terem mais três felinos, eles optaram por realizar a eutanásia do animal no CCZ de Salvador, devido à seriedade do quadro clínico e devido, também, à possibilidade de infestação dos animais contactantes e dos membros da família.

O segundo animal (Max) atendido na Mascot Pet Stella Maris, em Salvador/BA, residia no mesmo bairro. Após a confirmação do diagnóstico de Esporotricose, foi realizada a notificação compulsória ao Centro de Controle de Zoonese (CCZ) da cidade de Salvador, como é pedido na Portaria nº 191/2018. Para este animal foi fornecido o tratamento gratuito com Itraconazol $100 \mathrm{mg}$; porém, a dose utilizada foi de $50 \mathrm{mg}$ por animal (a proprietária mandou os comprimidos para uma farmácia de manipulação veterinária, a Drogavet, a qual realizou o fracionamento das cápsulas para esta dose de $50 \mathrm{mg}$ ). Após 60 dias de tratamento, a lesão já apresentava melhora (Figura 7) e após três meses de tratamento houve a total cura da lesão (Figura 8), ficando apenas uma região de cicatriz. O tratamento foi continuado por mais 30 dias após a cura da lesão, totalizando quatro meses de tratamento. Este animal foi testado para Leishmaniose pelos métodos ELISA e RIFI, tendo ambos os exames resultados negativos para tal doença. 


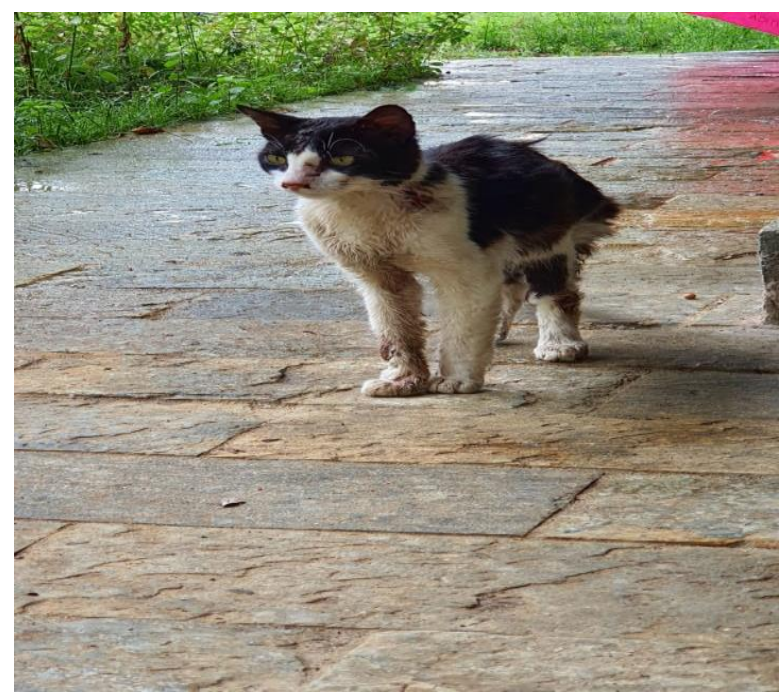

Figura 5. Animal com lesões de pele generalizadas e aspecto repulsivo.

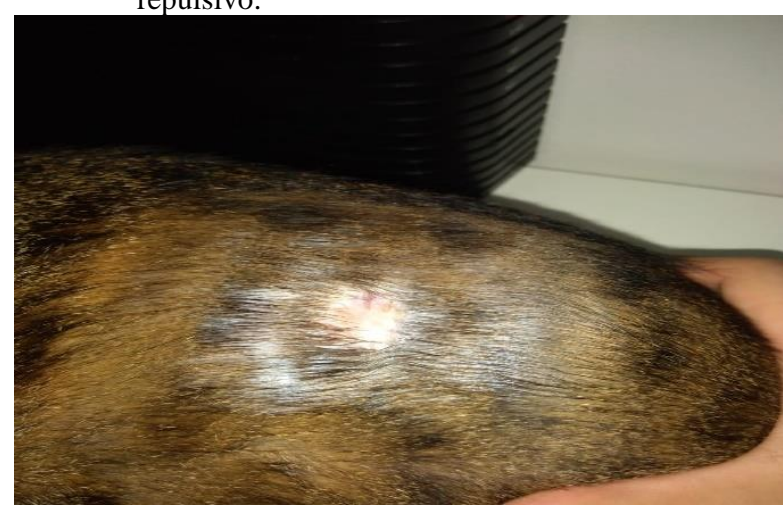

Figura 7. Lesão em animal Max após 60 dias de tratamento.

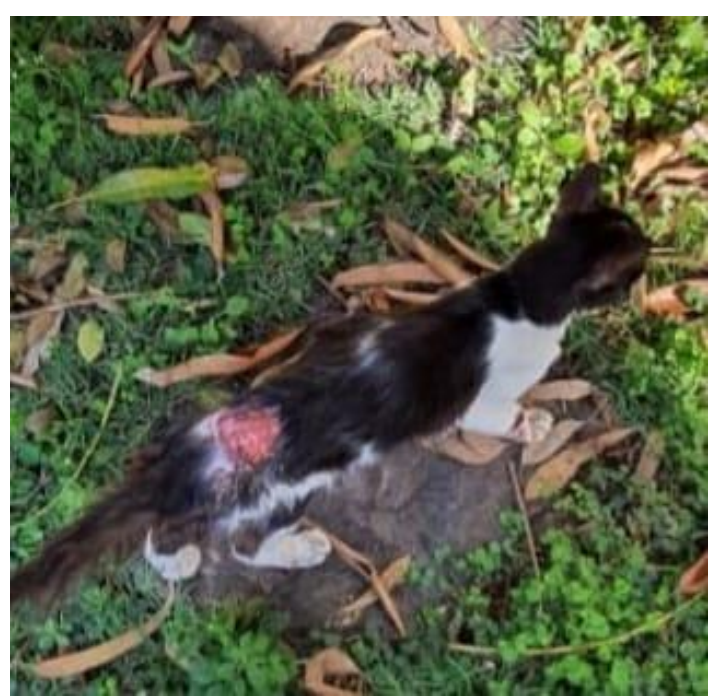

Figura 6. Animal com lesões de pele generalizadas e aspecto repulsivo.

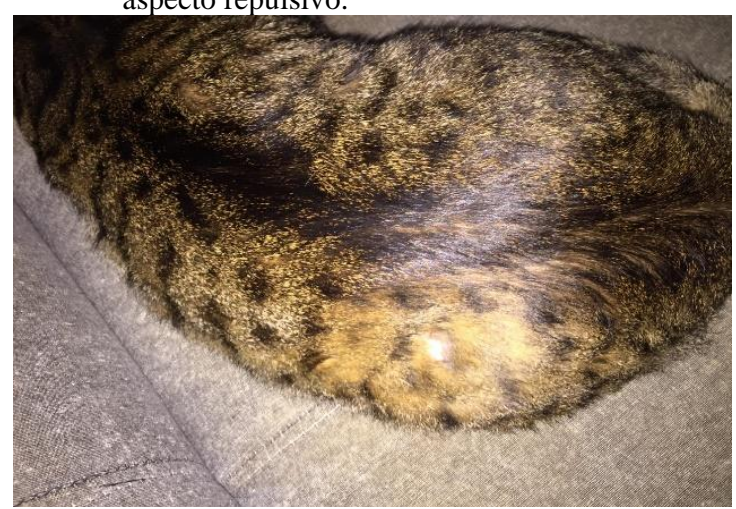

Figura 8. Animal após 3 meses de tratamento, com total cura da lesão.

\section{Discussão}

As doenças fúngicas representam a segunda dermatose mais frequente dos felinos domésticos e devem ser analisadas como prováveis diagnósticos quando o gato apresentar úlceras como lesões na pele (Larsson et al., 1996). O quadro clínico apresentado por gatos com esporotricose pode ir desde infecções subclínicas, passando por lesão única até lesões múltiplas e sistêmicas (Araújo \& Leal, 2016). As classificações das formas clínicas de esporotricose são: cutânea fixa ou localizada, cutâneo-linfática, cutânea disseminada, mucosa e extra cutânea ou sistêmica. A forma cutânea disseminada e a sistêmica são raras e estão quase sempre associadas à imunossupressão do hospedeiro. Já a forma mais frequente é cutâneo-linfática que é caracterizada pelo aparecimento de uma pápula endurecida, que se desenvolve a cerca de 7 a 30 dias após a inoculação (Araujo \& Leal, 2016; Pires, 2017; Silva et al., 2018). Os gatos dos relatos apresentaram dois dos tipos da doença, sendo o primeiro, Capitão, lesões múltiplas e sistêmicas, com lesões cutâneas disseminadas e o segundo, Max, lesão única ulcerada.

É importante excluir outras afecções granulomatosas, como: infecções bacterianas, micobacterioses atípicas, neoplasias, síndrome lepróide felina, leishmaniose, doenças alérgicas, autoimunes e outras infecções fúngicas como a criptococose e a histoplasmose, pois todas essas afecções mimetizam um quadro úlcero-granulomatoso (Rocha, 2014). Neste caso, no primeiro animal não foi realizado outros exames, pois foi realizada a eutanásia do animal e no segundo animal foram realizados exames para leishmaniose, com resultados negativos.

Para o diagnóstico de esporotricose, em ambos os casos foi realizada citologia por imprint de lâmina na lesão e posterior coloração com Romanowsky, sendo observada a presença de estruturas leveduriformes compatíveis com fungos do complexo Sporothrix spp (Figura 9). Este exame além de ser bastante prático, possui baixo custo para o proprietário. O exame citológico para felinos é muito útil, 
pois esta espécie, mais do que outras, apresenta uma elevada carga parasitária na maioria das lesões cutâneas, o que torna esta técnica muito eficiente para o diagnóstico da esporotricose felina (Cruz, 2010).

O antifúngico de eleição para o tratamento da esporotricose felina é o itraconazol, devido a sua efetividade e segurança, tornando-o superior quando comparado aos outros antifúngicos existentes para uso em animais (Araujo \& Leal, 2016). A dose do Itraconazol para felinos varia de 5 a $10 \mathrm{mg} / \mathrm{kg}$ uma ou duas vezes ao dia, porém estudos afirmam que a mesma pode variar de 30 a $100 \mathrm{mg} / \mathrm{kg}$ uma ou duas vezes ao dia, de acordo com a escolha do veterinário (Araujo \& Leal, 2016). Para o felino deste relato de caso, utilizou-se a dose de $50 \mathrm{mg} / \mathrm{kg}$ uma vez ao dia, durante quatro meses, sendo que após três meses a cura já era observada, porém continuou-se o tratamento por mais 30 dias após a total cura clínica, como é recomendado na literatura.

Casos vêm sendo relatados em vários estados do país, como surtos no Rio Grande do Sul e em Minas Gerais. Todavia, mesmo com alguns surtos já relatados no nordeste brasileiro, Rio Grande do Norte, Paraíba, Alagoas (Araujo \& Leal, 2016) e Bahia (Secretaria municipal de saúde de salvador, 2019), a esporotricose felina ainda é um assunto pouco explorado nesta região do país e se não for dada a devida importância a esta zoonose, corre o risco de o Nordeste se tornar uma área endêmica por falta de conhecimento (Araujo \& Leal, 2016).

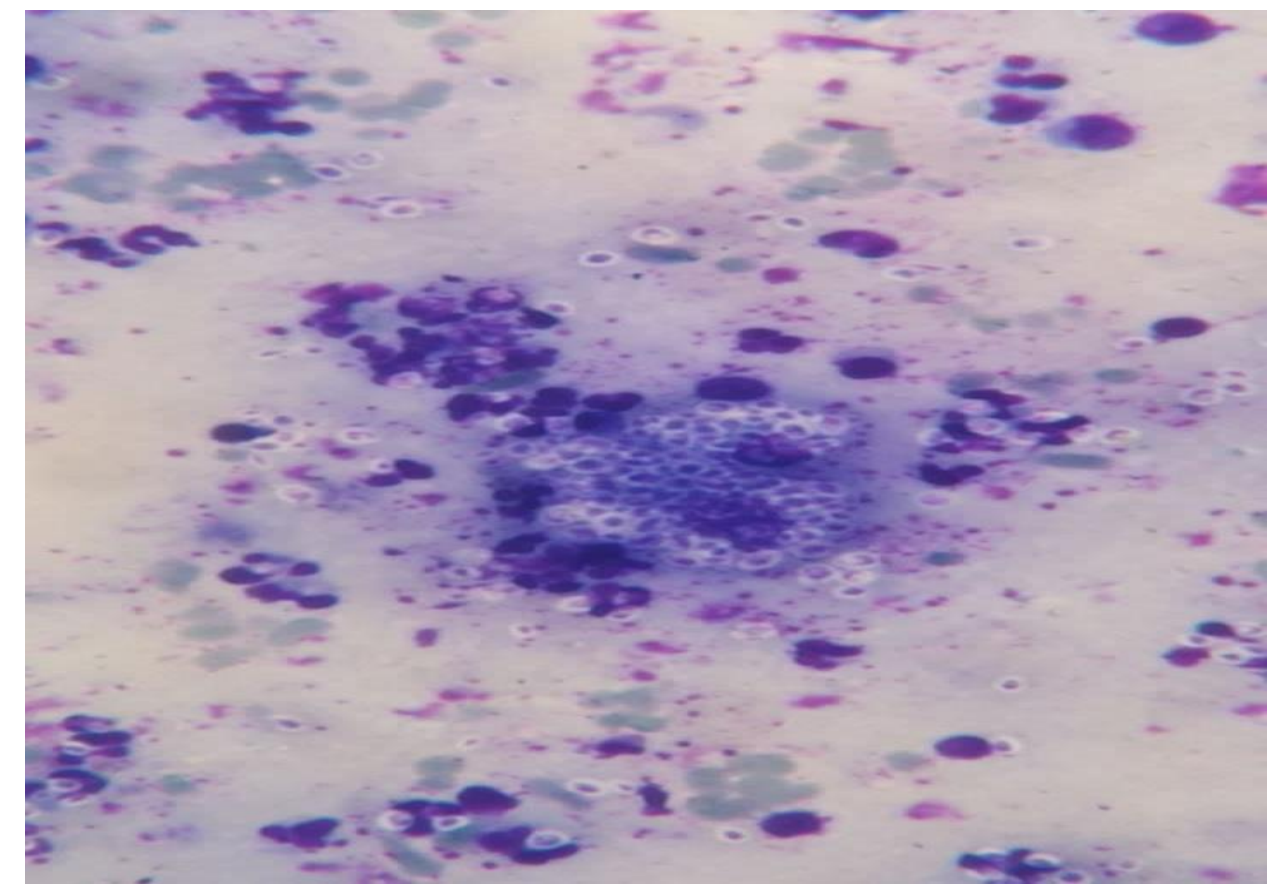

Figura 9. Lâmina corada pelo método Romanowsky com estrutura leveduriforme compatível com Sporothrix spp.

\section{Conclusão}

Este trabalho relatou dois casos de esporotricose felina na região metropolitana de Salvador, Bahia. Em um dos casos foi necessária a realização de eutanásia do animal devido a severidade das lesões e a este se tratar de animal errante. O segundo caso relatado foi de um animal semi domiciliar, o qual conseguiu obter a cura após um tratamento prolongado. Percebe-se então a importância de manter os felinos domiciliados, sem livre acesso á rua. Em caso de adoção de gatos que vivem na rua, os animais que apresentarem lesões características que levem á suspeita de esporotricose, devem ser levados ao médico veterinário para realização de exames a fim de descartar a doença, evitando a proliferação desta zoonose.

\section{Referência bibliográficas}

Almeida, A. J., Reis, N. F., Lourenço, C. S., Costa, N. Q., Bernardino, M. L. A., \& Vieira-da-Motta, O. (2018). Esporotricose em felinos domésticos (Felis catus domesticus) em Campos dos Goytacazes, 
RJ. Pesquisa Veterinária Brasileira, 38(7), 1438-1443. https://doi.org/10.1590/1678-5150-PVB5559.

Araujo, A. K. L., Gondim, A. L. de C. L., \& Araujo, I. E. A. (2020). Esporotricose felina e humanarelato de um caso zoonótico. Revista Brasileira de Higiene e Sanidade Animal, 14(2), 237-247. https://doi.org/10.5935/1981-2965.20200021.

Araujo, A. K. L., \& Leal, C. A. S. (2016). Esporotricose felina no município de Bezerros, Agreste Pernambucano: Relato de caso. PUBVET, 10, 795-872. https://doi.org/10.22256/pubvet.v10n11.816-820.

Barros, M. B. L., Schubach, T. P., Coll, J. O., Gremião, I. D., Wanke, B., \& Schubach, A. (2010). Esporotricose: a evolução e os desafios de uma epidemia. Revista Panamericana de Salud Publica, 27(6), 455-460.

Barros, M. S., Ferrari, H. J., Rezende, R. S., \& Faria, J. L. M. (2012). Esporotricose felina: primeiro relato de caso diagnosticado em Uberaba-Minais Gerais. Veterinária Notícias, 18(2), 110-120. https://doi.org/http://dx.doi.org/10.1590/S0103-84782012000500019.

Cavalcanti, E. A. N. L. D., Ignácio, T. C., Kunrath, S. E., Meinerz, A. R. M., Farias, R. O., \& Osório, L. G. (2018). Esporotricose: Revisão. PUBVET, 12, 133.

Cruz, L. C. H. (2010). Micologia veterinária (Vol. 1). Revinter.

Gonçalves, J. C., Gremião, I. D. F., Kölling, G., Duval, A. E. A., \& Ribeiro, P. M. T. (2019). Esporotricose, o gato e a comunidade. Encicloédia Biosfera, 16(29), 769-787. https://doi.org/10.18677/EnciBio_2019A62.

Larsson, C E, Otsuka, M., \& Michalany, N. S. (1996). El gato como fuente de infección en la esporotricosis humana: relato de casos en São Paulo (Brasil). In Congresso Panamericano de Ciências Veterinárias.

Larsson, Carlos Eduardo. (2011). Esporotricose. Brazilian Journal of Veterinary Research and Animal Science, 48(3), 250-259.

Nunes, G. D. L., Santos, R. C., Filgueira, K. D., Filgueira, F. G. F., \& Fernandes, T. H. T. (2013). Esporotricose felina no município de Itaporanga, estado da Paraíba, Brasil: relato de um caso. Arquivos de Ciências Veterinárias e Zoologia Da UNIPAR, 14(2), 157-161.

Pires, C. (2017). Revisão de literatura: esporotricose felina. Revista de Educação Continuada Em Medicina Veterinária e Zootecnia Do CRMV-SP, 15(1), 16-23. https://doi.org/10.36440/recmvz.v15i1.36758.

Rocha, R. F. D. B. (2014). Tratamento da esporotricose felina refratária com a associação de iodeto de potássio e itraconazol oral.

Rosa, C. S., Meinerz, A. R. M., Osório, L. G., Cleff, M. B., \& Meireles, M. C. A. (2017). Terapêutica da esporotricose: Revisão. Science And Animal Health, 5(3), 212-228.

Secretaria Municipal de Guarulhos. 2016. Determina Que Seja de Notificação Compulsória, de Importância Municipal, os Casos Suspeitos e Confirmados de Esporotricose Humana. Portaria N. 064/2016- Ss De 29 Jul. 2016. Diário Oficial, Guarulhos. P. 27.

Secretaria Municipal de Saúde de Salvador. 2019. Diretoria de Vigilância da Saúde. Situação Epidemiológica da Esporotricose em Salvador-BA. N6.

Silva, G. M., Howes, J. C. F., Leal, C. A. S., Mesquita, E. P., Pedrosa, C. M., Oliveira, A. A. F., Silva, L. B. G., \& Mota, R. A. (2018). Surto de esporotricose felina na região metropolitana do Recife. Pesquisa Veterinária Brasileira, 38, 1767-1771. https://doi.org/10.1590/1678-5150-pvb-5027.

\section{Histórico do artigo:}

Recebido: 20 de setembro de 2021 Aprovado: 22 de outubro de 2021

Disponível online: 11 de dezembro de 2021
Licenciamento: Este artigoé publicado na modalidade Acesso Aberto sob a licença Creative Commons Atribuição 4.0 (CC-BY 4.0), a qual permite uso irrestrito, distribuição, reprodução em qualquer meio, desde que $\mathrm{o}$ autor $\mathrm{e}$ a fonte sejam devidamente creditados. 